\title{
Playing into gender stereotyping in a pre- school theatre production
}

\begin{abstract}
This article gives a critical analysis of a nursery school (kindergarten/pre-school) play performance, in which lyrics and movement set the stage for gender stereotyping and sexualised behaviour. Using extracts of lyrics, the reader is invited to participate as an outsider and 'witness' (in accordance with narrative therapy tradition) to the way in which young children are placed as objects of stereotyping, in roles determined by the teacher play directors. To begin with the reader is introduced to socio-cultural psychology (specifically to the theory of childhood development) that focuses on the acquisition of gender roles. I argue that many school plays, especially at pre-school level, are developed for the entertainment of the (mostly) adult audience without considering what will be in the best interest of the young 'actors'. I refer to this as an act of perversion, while arguing that this is an educationally careless and irresponsible activity that prevails in school stage performances across a variety of schools in South Africa. I propose, rather, that a school play, as a cultural ritual should be employed as therapeutic tool to the aid of childhood development.
\end{abstract}

Keywords: school-play performance, gender stereotyping, sexualised behaviour, sociocultural psychology, early childhood development, sexual abuse

Elzette Fritz, University of Johannesburg. E-mail: elzettef@uj.ac.za.

South African Journal of Childhood Education | 2011 1(2): 112-126 |ISSN: $2223-7674$ |๑ UJ

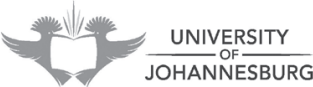




\section{An introduction: Looking at the stage}

Imagine that you are seated in a school hall in a middle to lower socio-economic residential area. The lights are slowly dimmed and the music starts. You are the parent to a five year old, soon to perform in his first nursery school play. The curtain rises and the group of five-year-old boys sway to the music of a popular Afrikaans song, "Leeuloop," (translated as "lion walk") that celebrates rugby, a nationally popular sport, but also other male dominated ball sports. The children enact on stage to the following instructions:

untie your pants and your belt gradually

the lion walk is very seductive

and I will explain it step by step

The boys are all geared with two tennis balls on a string and as the next verse begins, they turn their backs to the audience.

pinch two balls between your legs

with your hands and knees on the gravel

pull down your pants and roar

if you want

as long as you do the lion walk

tennis balls, cricket balls, snooker balls if you want...

The audience laughs, some people singing along to the catchy tune as the boys bend forward (backs to the audience) pulling down the extra pants they have on and swinging the two balls between their legs. This scenario repeats itself three times. The undertone to the lyrics, and the enacted movement, are not lost on the audience, but there is no obvious discomfort. You watch, thankful that your own son is not performing to this specific song, and later you will have to explain to him your adverse response to this performance in an age-appropriate manner, without undermining the teachers involved. You realise the other parents may not address this topic with their children, seeing as this is a difficult brief.

The group of boys leave the stage to a big round of applause and the music to "I'm a Barbie girl", performed by the group, Aqua, echoes through the auditorium. A group of four-year-old girls and boys walk on to the stage and, to the beat of the music, start swinging their hips, the girls pouting red painted lips as they sing along to:

I'm a Barbie girl in the Barbie world

Life in plastic, it's fantastic

You can brush my hair, undress me everywhere

Imagination, life is your creation

You're my doll, rock and roll, feel the glamour and pain

Kiss me here; touch me there, hanky-panky 
You can touch, you can play

You can say l'm always yours, oooh whoa

On stage, the boys embrace the girls, putting their hands on where flat chests will one day develop into breasts. Wolf whistles echo from the audience and people comment on how sexy some of the girls are. You notice that only a few of the children are smiling, enjoying their moment on stage. Most are performing robotic-like, glazed eyes looking over the audience as if the mind is somewhere else, probably trying to see a familiar parental face. Their 'spaced-out' expressions remind one of the dissociative states typically associated with trauma (Levine \& Kline, 2007), but also considered as a normal developmental coping mechanism (Watkins \& Watkins, 1997).

The next song is performed by a four-year-old girl singing "I'm a single girl" by Sandy Posey:

The single girl all alone in a great big town

The single girl gets to tired of love letting her down

The life's unreal and the people are homely

And the nights can get so lonely

The single girls needs a sweet lovin' man to lean on.

You pay careful attention to the lyrics, the implied disappointment in love, then ensuing loneliness and the fact that a girl needs a man to take care of her. You wonder what sense the four year old is making of the themes so 'innocently' sung on stage. The concert ends to "I had the time of my life" from the film Dirty Dancing, which brings to mind images from the movie in which Patrick Swayze and Jennifer Gray dance on stage after Gray's character (Baby) has transformed from girl to woman. Your eyes scan through the programme of the evening, and you notice that of the twenty-one items, only one well-known, rather outdated, children's song is included, the rest are all adult appropriate with more than half falling in a category related to romantic/sexual relationships. On stage you witnessed 'babies' emulating grown-ups in dress, manner, song and movement and you wonder how the story of this play assists in blatantly depriving these children of innocent child theatre, exposing them to the world of stereotypical sexualised behaviour and role modelling.

Your mind goes back to when you were in nursery school, in a community not to different from this one. You still have photos of the event. You vaguely remember singing a nursery rhyme in a group, swaying to and fro; there was no choreographed movement then. There was barely any rehearsal before the big event and parents cheered, just for the pleasure of seeing their little one on stage.

At the end of the evening, you take your son home. He is tired after the big event. He mumbles that he will not participate in the next play; they practised too much and some of the teachers shouted when their movements were not in unison. In the following days, you hear him singing some of the lyrics as he plays with his Lego blocks and figurines, humming the lyrics to the songs, which he did not perform on stage. In conversation, you hear him speaking of the girls chasing after the boys, playing kissing 
touches and you wonder if this game, where the aim is for a girl to catch a boy in order to kiss him, can be linked to the concert where a sexual undercurrent was tangible. While thinking this, you also keep the context of current childhood influences in mind, considering the television programmes and Playstation games your child is exposed to, and the community in which you reside (Bronfenbrenner, 2005). You are subsequently left with the question of what the school-play performance signifies.

\section{From the stage to a conference}

To invite the reader to participate further in the interpretation of the school play production, imagine that you have just attended the South African Professional Society on the Abuse of Children (SAPSAC) conference, where the topic of the sexual abuse of children was specifically addressed. A police detective shared case studies of babies that had been raped, and a representative of the Gauteng Department of Education introduced the audience to four children, ages ranging from pre-school to 10 years, who had been abused by people in their families. Imagine you heard the South African statistics being read to you; roughly $33 \%$ of girls, and $14 \%$ of boys are molested before the age of 18 (Labuschagne, 2010). In South Africa it is reported that a sex crime occurs every 20 seconds (Anonymous, 2005). The number of crimes committed against children in South Africa seems to be on the rise. 72000 crimes against children were reported in 2000, with assault and sexual abuse taking the lead. Infants and young children are often the victims of the vilest criminal offences (Berry \& Guthrie, 2003). Imagine hearing of how children are groomed for sexual abuse from a young age, most often by people within their families; and how television, computer games and the film industry de-sensitise children to violence, as well as, sexually inappropriate behaviour. Reference is made to how children are, from an early age, conditioned to identify with stereotypically aggressive models, such as WWE Wrestlers (in the case of boys) and sexy icons, such as the Bratz girls, through infant clothing and toys (Bird, 2010).

Now consider the Children's Bill of Rights' statement that children should be involved in decisions and actions that affect them (UNICEF, 2009; Tisdall, 2010). Children may also not perform work, or provide services that are inappropriate in relation to their developmental stage, or be placed at risk with regards to their wellbeing, education, physical or mental health or spiritual, moral or social development. The South African Children's Amendment Act (Republic of South Africa, 2008) states that early childhood development programmes must provide children with appropriate developmental opportunities that will support children in realising their full potential; thus ensuring development of positive social behaviour as well as respecting and nurturing their culture, spirit, dignity, individuality (in terms of the language and development of each child), while meeting the emotional, cognitive, sensory, spiritual, moral, physical, social and communicative development needs of children. As such, a child's best interests should be of paramount importance in every matter concerning the child. I concur with Evans (2001) that all early childhood activities should provide children with the best possible intellectual, physical and social tools and experiences 
to enable them to reach their highest intellectual, physical and social capacities. More seriously, they should be protected from acting out semiotic mediation that ignores their age (Postman, 1994). One can question if children's rights are ever considered when school plays are organised, when lyrics are selected and choreography planned, for the stage performance of especially young children. Fritz, Henning and Swart (2008) asked this question in a study of a primary school play production in which they found that the teachers who were producing a play were seeing themselves as the target audience; and for this reason produced a play for an adult audience and for their own theatrical, cathartic experience. My argument in this article is that it is critical that the children's acting, singing and dancing should, epistemologically, be aimed at a child audience. The parents and other adults who come to watch the production are almost 'props' in the audience. Children, in a school production, need to participate as part of a cultural celebration, so as to learn. Do teachers, nursery school teachers in particular, think about what children learn as they perform lyrics, wear costumes, use props and make movements on stage?

\section{Sociocultural psychology and stage(s) of child development}

To interpret the scenarios that I have just depicted I view the scenario data from the psychologies that have evolved from Vygotsky's work on child development. According to Vygotsky (1934/1978/1986/1992), human development is a 'cultural' phenomenon in that the semiotically mediated world of the growing child plays a large part in development. On this view, young children engage in their social environment, and it is through this act of interaction that their development occurs (John-Steiner \& Mahn, 1996). This view is supported by Rogoff (1993; 2003), who sees learning to engage with culture as a development that happens in stages of increased participation. I use her expansion on Vygotskian theory as the organising framework with which to discuss the stages of childhood development. In such a framework individual activity is not an internal manifestation of an individualised, intrapsychic process or the lawful patterns of responses to external stimuli, as some innatists would have it (Smith, 2001). Vygotsky (in John-Steiner \& Mahn, 1996, p. 192) proposed that development could be regarded as the transformation of "... socially shared activities into internalized processes". In this way he rejected the Cartesian dichotomy between the internal and the external.

In order to understand the interplay between internal and external influences on development, Rogoff proposes three planes of activity, which occurs within a group based on various aspects of participation referred to as apprenticeship, which occurs on the community (viz. interpsychological) plane. According to Rogoff, individuals, in this case the children participating in a school performance undergo a process of socialisation based on their engagement in a specific community. The children develop according to the guided participation in the school play, as directed by their teachers, which occurs on the interpersonal plane. The children then internalise on the personal plane what is deemed appropriate through the interaction with each other on stage. As such, development commences within the group as a whole, between 
individual members, and within the individual member (Rogoff, 1993, p. 141). These sociocultural views of participation are based on a belief in "an interdependence of individual mind, interpersonal relations and social situations that enable learning or development" (Heath \& McLaughlin 1994, p. 473). Learning can, therefore, not be regarded as an independent, individual process with social aspects, but rather the result of participation in a community.

In a similar vein, Veresov (2004) referring to Vygotsky (1983, p. 145) explains that any function in the child's cultural development appears 'on stage' (in the original Russian and in the theatrical discourse that Vygotsky used in some of his writing) twice, that is, on two planes. Firstly, a child develops on the social plane, among people on an inter-psychological level. Then the child develops on a psychological plane on an intra-psychological level, the 'second stage', or part of the theatrical stage. According to Veresov, the words 'on the stage' and 'on two planes' are not metaphors, which might be omitted or ignored. He explains 'stage', by referring to the Russian meaning, according to which 'scene', or the 'arena', literally refers to the place in the theatre where actors play. The concept 'scene', therefore also resonates on two 'planes'; the front plane (also referred to as 'the first plane' and which could be seen as 'upstage' in theatrical discourse), and the back plane (often referred to as 'the second plane', or 'downstage' in theatrical discourse). Situating the language of one of the central tenets of Vygotskian theory of development in the language of theatre, 'participatory action' (Rogoff, 1991), in the culture is thus acting on both 'planes'. The main events of the 'performance' of learning and development, according to theatre's tradition, should happen on the front plane of the scene, or 'upstage' where the other cultural participants, such as parents and elders, can see it clearly. On this view, then, human development occurs, interactively, on two planes: inter-psychologically (on the first, front plane) and then intra-psychologically (on the second internal, individual plane). In the 'downstage' of individual action scenes are not as prominently exhibited as in the 'upstage' area. Similarly, intrapersonal development is not as prominent as interpersonal interaction.

So, the image that Vygotsky used is now an image-come-to-life. The signs and the symbols (the semiotic content) that these children physically embody through movement, in song and speech, are the messages that the school and its culture project in a tangible way. While young children learn through mediated, semiotic action, they are also scaffold to reach the outer limits of their potential at any given moment, by way of "dramatical collisions" (Veresov, 2004) on the "stage of their minds". The concept of dramatic collisions, as described by Veresov, pertains to the contradictions between the child and the social setting, in terms of the child's level of development and demands of the social surroundings. These collisions can be regarded as moving forces of development that relate to the "zone of proximal development" (Vygotsky, 1978, p. 86). Veresov describes childhood development as occurring on different levels of development in different functions in the child. At each stage of development, there may already be developed functions, which he describes as “...'fruits' of development, and there are functions that are in a process of maturation; the 'buds' 
or 'flowers' of development" (Veresov, 2004, p. 13). According to Zinchenko (1996, p. 8 in Veresov, 2004, p. 9), development can therefore be characterised according to cultural-historical psychology, "as a drama played concerning interaction of real and ideal forms", with 'ideal forms' referring to the culture to which a child is exposed to since birth. In the case of the school-play performance that I describe the culture is reflected by the semiotics that are mediated; here young children entertain adults, acting to adult lyrics, simulating adult movements, with strong sexual undercurrents, and presenting themselves as 'little adults' to the applause of the audience. This all happens in a public space with the stamp of approval of the school, thus authorising the event as a cultural celebration. From the view of developmental psychology the children are indeed acting out the scenes of the future, but not as Vygotsky originally theorised play as a tool for advancement in the ZPD.

\title{
"Performing a head taller than they are"
}

According to Vygotsky (1966/1933, p. 101):

\begin{abstract}
Play creates a zone of proximal development of the child. In play the child always behaves beyond his average age, above his daily behaviour; in play it is as though he were a head taller than himself. As in the focus of magnifying glass, play contains all developmental tendencies in a condensed form and in itself a focus of magnifying glass, play contains all developmental tendencies in a condensed form and in itself a major source of development.
\end{abstract}

Hence the question, if children learn and develop, by "performing a head taller than they are" (Vygotsky, 1978, p. 102), while engaging in a school-play performance as the one described, is it scaffolding learning to their advantage, or does it place the young children in a compromising situation? If one does not take into account that these are five-year olds, the scenes that I have witnessed may be described as scenes in which 'being' female is signified by acting as sexual sirens, or helpless victims. The male performers can be seen as male testosterone fuelled predators.

Young children learn through aesthetics, by engaging in play through art, music, movement, drama, story and performance as much as they learn by way of instruction (Henning, 1981; 1991). Classical theorists of child development such as Piaget (1969), Vygotsky (1978), and Bruner (2006), as well as contemporary theorists such as Gopnik and Meltzhoff (1997) and Carey (1985; 2009) foreground play as a developmental medium. There is no doubt a very powerful tool in play of various types. Play is a powerful tool for 'mediated action' forms that scaffold young children's entry into a culture, whether it is of learning mathematics, or learning to practice a code of conduct, or learning how to be a member of a culture in the public spaces of citizens. It makes sense that much of Vygotsky's terminology comes from his involvement in the theatre world of Moscow in the 1920s (Veresov, 2007; Whitelaw, De Beer \& Henning, 2008) and it is evident in the analysis of his work by Russian scholars such as Veresov (2004; 2007) and also in the work of Jerome Bruner (1986; 2006).

What I wish to highlight for the interpretation of the school play production is that the social interaction that happens during scaffolding and mediation is internalised 
as a package. From this view Vygotsky argues that it is not the "higher psychological functions' of an individual alone that scaffolds learning (and learning to be), but that all learning is a form of social interaction, and that it is the social interaction itself that is internalised (see also Henning, 2008). Vygotsky says, in this regard about play, "[t] he problem is that it is nearly impossible to define ZPD in play on the basis of the basic principle of the operation of the higher psychological functions (= personality)," while it "can be accomplished to the full extent in the form of drama" (Vygotsky, 1986, p. 55). The 'drama', according to Veresov, can be accomplished in its basic form in any classroom, but when education ventures to the public space of an open stage, it takes on another and almost more daring form. It is in this space that I discuss the school performance referred to in the article. It is also in this space that I wish to argue for the use of school drama performances as therapeutic interventions, that is, as zones of proximal development in which children and youth can safely 'play' with the elements of their lives that they find obstructive. Thus I want to turn the idea of the current form of the school production that I described on its head.

\section{What really happens on the school stage?}

I wondered what children learn about themselves, others, as well as their own sexual identity, when they participate in school plays, such as the one I have described? To my mind this is a very relevant question if you consider that in the community where this school performance occurred, children will be involved in at least two nursery school plays if they entered the school at the age of three. Then add another three performances in primary school (one every second year) and a further three in secondary school. Now keep in mind, children rehearse for the play at least 10 to 20 times before it is presented to the audience; often in two to three shows. During this time lyrics and movements are rehearsed on the different stages of development that is subsequently internalised and possibly automised. If play creates a zone for proximal development (Vygotsky, 1977), the implication is that children can learn about their gendered role by acting on stage. This is aligned to research by Lave (1996) that focuses on the socialising effects of schooling and identity formation.

\section{Sexual stereotyping and role modelling}

To my mind, very specific cultural gender stereotypes were presented by the children while acting out the play. Gender role identity and sexuality starts already during infancy, based on behaviour that is related to what a society or community regards as typical to being a male or female (De Witt, 2009; Freeman, 2007). According to social cultural theory, all gender differences can be regarded as the socially acquired product of culture, influenced by physical, cognitive, social and emotional dimensions (De Witt, 2009). As such, a school play that engages pre-schoolers in sexualised movements, accompanied by music with sexualised lyrics, exposes the children to implicit gender stereotyping. This is a cause for concern when one considers the dramatic collisions 
between these children's current developmental stage, and that which is presented as the 'ideal' by their teachers.

Large parts of South Africa are patriarchal with the understanding that men posses power over women and children. This is exacerbated to the extent of possibly manifesting as physical violence and even sexual abuse (Richter \& Daves, 2008). According to Townsend and Dawes (2004) socialisation practices perpetuate behaviour ascribed to male and female adults and children. This is where the question can be asked, what happens if children in their early childhood see the world with the eyes, speech and movement related to the sexual stereotypes of the adults scaffolding their development?

The process of stereotyping occurs, as an individual is unable or unwilling to react to a person as an individual, but rather classifies the person based on assumptions founded on rigid traits and group classification. This knowledge develops during the pre-school years and reaches a ceiling by the age of five to six years (De Witt, 2009). The songs sung in this concert subscribed to the typical Western stereotype of females (Hopkins, 1983) as being passive, emotional, and subservient, and ever in search of a male to take care of her. A school play can, therefore, become a powerful tool to either support non-biased and gender-fair play (Evans, 1998) and role identification, or lay a foundation of stereotypical behaviour.

\section{Process-oriented art towards enhanced cultural learning}

Similar to Vygotsky (Lim, 2004) creative expressive arts therapists such as McNiff (2004) and Malchiodi (2003), agree that children's artwork should not be product driven, but rather process orientated. So, how can school-play performances be planned and presented while considering the seminal work of Vygotsky and those that follow? I argue that a school play should be planned and produced according to the stages of childhood development. Instead of adults selecting popular adult songs, lyrics for school-play performances need to be selected through the active engagement of children. The whole process of song selection can in itself present a learning opportunity to engage children in thinking what they like about the music they listen to, what grabs their attention when they listen to a song and how they can move to the music. Costumes need to be tailored to suit the developmental level of child performers, by, once again, engaging children in the process of the stage production. A school play should present children with 'an experience', since an event that is intrinsically enjoyable creates excitement and that holds immediate meaning (Cuffaro, 1995). Young children, in preparation for abstract conceptual thinking, use art through play to make sense of the world. As such, "learning becomes meaning-making when children engage their mind, and art is a primary path for this achievement" (Lim, 2004, p. 484). 


\section{From exhibiting children to using a school play as a therapeutic opportunity}

I regard play, including 'play on stage', as a powerful tool for expressive arts therapy (McNiff, 2009; 2004; 1992; Malchiodi, 2003; 1997). With reference to the cultural, historical origins, and the home of Vygotsky's work (Stetsenko, 2004) theatrical, dramatic expression can be utilised to do what the production I described did not do. Through play children make sense of their world, take responsibility for actions, develop new concepts, increase their social skills and are supported emotionally (Jessee \& Gaynard, 2009). Research (Sullivan, Kehle \& Bray, 2009) indicates that there is a link between learning and relationships. My argument is that if schoolplay performances can enhance relationships through fostering a "healing setting" (Wampold, 2001), it will also contribute towards the learning development of children (Rimm-Kaufman \& Chin, 2007).

School plays can perform the function of 'edutainment' for parents and teachers, or it can truly be scaffolding for experiences of the young. Organised activities that are playful, in particular, are capable of providing a learning and supportive opportunity (Hakkarainen, 2006). In the latter case, teachers, as 'master practitioners' will consider the learning potential a play performance holds for their young 'apprentices'. I argue, considering the South African landscape, that a school performance can be utilised as a school community intervention through the purposeful engagement of children in music, song, movement, dance, drama and other forms of creative expression. By doing this, the 'master' can assist the 'apprentice' in finding solutions to everyday problems (Hedegaard, 1998), e.g. how to regard gender, through the focused engagement in a school-play performance. When considered in this way, a school play is an ideal opportunity for enriched learning, especially with the integration of various art forms, such as song, movement and dance. School-play performances, as such, need to be informed by,

a) Children's everyday life situations and challenges characteristic of their community;

b) Subject matter that is deemed relevant for their learning; and

c) Their engagement on and off stage contributing towards development, considering leading childhood development theories.

\section{Conclusion}

So, sitting in the school hall and witnessing nursery school children gyrating to adolescent/adult lyrics, the question comes to mind as to how school-play performances can be utilised as a celebration of childhood towards scaffolded learning (Fritz et al., 2008). How can adults use the ritual of school-play performance to create developmental spaces considering the different stages of development? I would like to 
conclude by creating an alternative performance contrary to the one I initially shared with the reader.

So, again, imagine you are seated in a school hall in a middle to lower socioeconomic residential area. The lights are slowly dimmed and the music starts. You are the parent to a five year old, soon to perform in his first nursery school play. The curtain rises and the group of five-year-old children sway to the beat of African drums, with the song "We are one" from the Lion King, playing in the background.

\author{
But you'll see every day \\ That we'll never turn away \\ When it seems all your dreams come undone \\ We will stand by your side \\ Filled with hope and filled with pride \\ We are more than we are \\ We are one
}

As you watch, you suddenly understand why your son spoke about wild animals lately and how each animal relies on another for survival. He initially wanted to be the king of the lions, but once he realised Rafiki, meaning 'friend' in Swahili, is actually a wise person and similar to a medicine man (to his mind therefore a doctor), he became excited to play the role. You notice the enthusiasm with which the group of children in the corner are beating the drums. The performance of the children can be described as energetic to the point of being slightly chaotic. Their smiles are broad and you remember how you had to assist your child in preparation for his transformation into Rafiki. Seeing as the cost of the school play had to be minimal, the children were engaged in how they could present their characters on stage, and, therefore, they had to use their imaginations in the development of their costumes and props. Old stockings became tails, hair-bands were used to create ears with a bit of cardboard; children were engaged in painting hardboard trees, and one of the more withdrawn children volunteered to be a rock on stage.

As the performance continues, you recall the conversation you had with your son regarding how it came about that they would be performing The Lion King. He explained how they were asked to share their favourite movies and they then had to vote for the one they would perform, after they first had a discussion about the meaning of each story. He explained that their roles were ascribed based on their personality types. You remember the meeting you attended during parents' evening where a psychologist, knowledgeable in the field of creative expressive art therapy and early childhood development, informed the parents and teachers that the participation of the children took preference over perfection in movement. She emphasised the importance of mass participation and that even the children who did not want to perform on stage, would still be involved in the planning of the performance. She also explained how children learn in interaction with each other and develop social skills as well as learn about themselves as they engage on stage. 
Later that evening, as you drove your exhausted but happy child home, you were grateful for a school where teachers gave preference to the learning of those in their charge, as opposed to engaging children in activities for the benefit of the teachers. You appreciate all the energy they invested in tailoring the play to the developmental needs of the children, engaging the children in decision-making, being sensitive to the multi-cultural population of the school and steering clear of sexual stereotypes.

\section{Word of appreciation}

I would like to express my appreciation to Elbie Henning, who acted as critical reader and provided scaffolding to this article.

\section{Bibliography}

Anonymous. (2005). Worldwide sexual assault statistics. George Mason University Sexual Assault Services. Retrieved May 29, 2010, from http://www.gmu.edu/depts/unilife/ sexual/brochures/WorldStats2005.pdf.

Berry, L. \& Guthrie, T. (2003). Rapid assessment: The situation of children in South Africa. University of Cape Town: Children's Institute.

Bird, W. (2010). Child Abuse and the Media: With emphasis on the role of the media in the expression of sexualised behaviour. SAPSAC conference, Pretoria.

Bronfenbrenner, U. (Ed.). (2005). Making human beings human: Bioecological perspectives on human development. London: SAGE Publications.

Bruner, J.S. (1986). Actual minds, possible worlds. Cambridge, MA: Harvard University Press.

Bruner, J.S. (2006). In search of pedagogy, Vol 1. The selected works of Jeremy S. Bruner. New York: Routledge.

Cuffaro, H.K. (1995). Experimenting with the world: John Dewey and the early childhood classroom. New York: Teachers College Press.

De Witt, M.W. (2009). The young child in context. A thematic approach. Perspectives from educational psychology and sociopedagogics. Pretoria: Van Schaik.

Evans, J. (2001). Eight is too late. Investment in early childhood development. Journal of international affairs, 55(1), 91-109.

Evans, K.S. (1998). Combating gender disparity in education: Guidelines for early childhood educators. Early Childhood Education Journal, 26(2), 83-87.

Freeman, N.K. (2007). Pre-schoolers' perceptions of gender appropriate toys and their parents' beliefs about genderised behaviours: Miscommunication, mixed messages, or hidden truths? Early childhood Education Journal, 34(5), 357-366.

Gopnik, A. \& Meltzoff, A.N. (1997). Words, thoughts, and theories. Cambridge, Mass.: Bradford, MIT Press. 
Republic of South Africa. (2008). Children's Amendment Act, No. 41 of 2008. Pretoria: Government Printers.

Hakkarainen, P. (2006). Learning and development in play. In J. Einarsdottir and J. Wagner (Eds.). Nordic childhoods and early education, p. 183-222. Connecticut: Information Age Publishing.

Heath, S.B. \& McLaughlin, M.W. (1994). Learning for anything everyday. Curriculum Studies, 26(5), 471-489.

Hedegaard, M. (1998). Situated learning and cognition: Theoretical learning and cognition. Mind, Culture, and Activity, 15(2), 114-126.

Henning, E. (1981). The role of dramatic play in primary education. Unpublished MA dissertation, University of Pretoria, Pretoria, South Africa.

Henning, E. (1991). Drama-making in ESL teaching: The need for classroom-based research. Journal for Language Teaching, 25(2), 96-104.

Holzman, L. (2006). Lev Vygotsky and the new performative psychology: Implications for business and organizations. In D.M. Hoskins and S. McNamee (Eds.). The social construction of organisation. Copenhagen: Copenhagen Business school Press.

Hopkins, J.R. (1983). Adolescence: The transitional years. New York: Academic Press.

Fritz, E., Henning, E. \& Swart, E. (2008). When all the school became a stage: Young children enacting a community's sense of fear and loss. International Journal of Qualitative Studies in Education, 21(4), 375-387.

Jessee, P.O. \& Gaynard, L. (2009). Paradigms of play. In R.H Thompson (Ed.). The handbook of child life, p. 136-159. Illinois: Charles C. Thomas Publishers.

John-Steiner, V. \& Mahn, H. (1996). Sociocultural approaches to learning and development. A Vygotskian framework. Educational Psychologist, 31(3/4), 191206.

Labuschagne, T. (2010). Child abuse: An educational perspective. SAPSAC conference. Pretoria.

Lave, J. (1996). Teaching, as learning, in practice. Mind, Culture and Activity, 3, 149-164.

Levine, P. \& Kline, M. (2007). Trauma through a child's eyes: Awakening the ordinary miracle of healing. Berkeley: North Atlantic Books.

Lim, B. (2004). Aesthetic discourses in early childhood settings: Dewey, Steiner, and Vygotsky. Early Childhood Development and Care, 174(5), 473-486.

Malchiodi, C.A. (Ed.). (2003). Handbook of art therapy. New York: The Guilford Press.

Malchiodi, C.A. (1997). Breaking the silence: Art therapy with children from violent homes. ( $2^{\text {nd }}$ ed.). New York: Brunner/Mazel.

McNiff, S. (2009). Art-based research. Philadelphia: Jessica Kingsley.

McNiff, S. (2004). How creativity cures the soul. New York: Shambhala.

McNiff, S. (1992). Art as medicine. Creating a therapy of imagination. Boston: Shambhala. 
Piaget, J. \& Inhelder, B. (1969). The psychology of the child. New York: Basic Books.

Postman, N. (1994). The disappearance of childhood. New York: Vintage/Random House.

Richter, L.M. \& Dawes, A.R.L. (2008). Child abuse in South Africa. Rights and wrongs. Child Abuse Review, 17, 79-93.

Rimm-Kaufman, S.E. \& Chiu, Y.I. (2007). Promoting social and academic competence in the classroom: An intervention study examining the contribution of the responsive classroom approach. Psychology in the Schools, 44, 397-413.

Rogoff, B. (1993). Observing sociocultural activity on three planes. In J.V. Wertsch, P. del Río and A. Alvarez (Eds.). Sociocultural studies of mind, p. 139-163. New York: Cambridge University Press.

Rogoff, B. (2003). The cultural nature of human development. Oxford: Oxford University Press.

Stetsenko, A. (2004). Introduction to "tool and sign in the development of the child". In Vygotsky, Rieber, Robinson and Bruner (Eds.). The essential Vygotsky, p. 501-512. New York: Kluwer Academic/Plenum Publishers.

Sullivan, E., Kehle, T.J. \& Bray, M.A. (2009). Application of the contextual model to schoolbased counselling: Why does it work? Psychology in Schools, 46(3), 299-305.

Tisdall, E.K.M. (2010). Governance and participation. In B. Percy-Smith and N. Thomas (Eds.). A handbook of children and young people's participation. London: Routledge.

Townsend, L. \& Dawes, A. (2004). Individual and contextual factors associated with the sexual abuse of children under twelve: A review of recent literature. In L. Richter, A. Dawes and C. Higson-Smith (Eds.). Sexual abuse of young children in southern Africa, p. 55-94. Cape Town: HSRC Press.

UNICEF. (2009). The state of the world's children. Special edition. Celebrating 20 years of the convention on the rights of the child. New York: United Nations Children Fund.

Veresov, N. (2004). Zone of proximal development (ZPD): The hidden dimension? In A. Ostern, R. Heila-Ylikallio (Eds.). Language as culture - tensions in time and space, p. 13-30. Vasa.

Vygotsky, L. (1977). Play and its role in the mental development of the child. In M. Cole (Ed.). Soviet developmental psychology, p. 76-99. White plains, NY: M.E. Sharpe.

Vygotsky, L.S. (1978). Mind in society: The development of higher psychological process. Cambridge, MA: Harvard University.

Wampold, B.E. (2001). The great psychotherapy debate: Models, methods and findings. Mahwah, NJ: Lawrence Erlbaum Associates.

Watkins, J. \& Watkins, H. (1997). Ego states: Theory and therapy. New York: W.W. Norton \& Company.

Whitelaw, S., De Beer, J. \& Henning, E. (2008). New teachers in a pseudo-community of practitioners. Education as Change, 12(2), 25-44. 
Zinchenko, V. (1996). Developing activity theory: The zone of proximal development and beyond. In B. Nardi (Ed.). Context and consciousness: Activity theory and humancomputer interaction. Cambridge: MIT Press. 